\title{
Mestrado Profissional em Educação: reflexões acerca de uma experiência de formação à luz da autonomia e da profissionalidade docente
}

\section{Professional Masters in Education: reflections on a training experience in the light of teacher autonomy and professionality}

\author{
Marília Andrade Torales Campos ${ }^{1}$ \\ Ettiène Guérios ${ }^{1}$
}

\begin{abstract}
RESUMO
O compromisso das instituições de Ensino Superior com a formação dos profissionais que atuam na Educação Básica tem sido tema de discussão em diferentes momentos históricos e políticos. No cenário das políticas públicas de Pós-Graduação no Brasil, os Mestrados Profissionais se apresentam como um novo elemento ao debate, tendo em vista que suas características estão direcionadas ao desenvolvimento profissional dos sujeitos. No caso desta reflexão, se trata de pensar o potencial de contribuição que esta realidade, emergente num horizonte de múltiplos desafios, pode ter para o desenvolvimento da autonomia e da profissionalidade dos professores. Sendo assim, o presente artigo se propõe a realizar uma reflexão sobre o processo de estruturação e implementação de um Programa de Pós-Graduação na área da Educação a partir da compreensão dos conceitos de autonomia e profissionalidade docente, tomando como base teórica as abordagens sustentadas por Gimeno Sacristán (1995), Tardif (2002), Contreras (2002) e Morgado (2005 e 2011), dentre outros. O referido Programa, que toma por objetivo a formação de professores e pedagogos que atuam em escolas da Educação Básica, é analisado a partir de diversas perspectivas, partindo
\end{abstract}

DOI: $10.1590 / 0104-4060.49806$

1 Universidade Federal do Paraná. Setor de Educação. Curitiba, Paraná, Brasil. Rua General Carneiro, nº 460. CEP: 80060-150.E-mails: mariliat.ufpr@gmail.com e ettiene@ufpr.br 
do processo de estruturação do Programa até a composição e definição do perfil do corpo docente.

Palavras-chave: Mestrado Profissional; Educação Básica; autonomia; profissionalidade.

\begin{abstract}
The commitment of Higher Education institutions with the training of professionals working in Basic Education has been the subject of discussions in different historical and political moments. In the setting of public policies on graduation in Brazil, the Professional Masters are presented as a new element to the debate, given that its features are directed to the professional development of individuals. This reflection focuses on the potential contribution of this emerging reality to the development of teacher autonomy and professionality within a horizon of multiple challenges. Therefore, the aim of this paper is to carry out a reflection on the process of structuring and implementing a Postgraduate Program in Education based on the understanding of the concepts of autonomy and teaching professionality, having as theoretical basis the approaches by Gimeno Sacristán (1995), Tardif (2002), Contreras (2002) and Morgado (2005 and 2011), among others. This Program, which aims at the training of teachers and educators who work in Basic Education schools, is analyzed from different perspectives, assuming that the composition and definition of the faculty profile result from the very conception and purposes of the Program.
\end{abstract}

Keywords: Professional master; Basic Education; autonomy; professionality.

\title{
Introdução
}

O discurso dominante no campo pedagógico, por vezes, promove uma hiper-responsabilização dos professores em relação à prática pedagógica e à qualidade do ensino. (GIMENO SACRISTÁN, 1995). No entanto, não seria coerente atribuir toda a responsabilidade sobre o processo pedagógico a estes profissionais, tendo em vista que é preciso reconhecer sua indiscutível importância para a sociedade e para o exercício da cidadania, mas sem perder de vista o macro contexto em que estão inseridos. Como diz Imbernón (2016, p. 51), “[...] não será possível enfrentar o futuro sem ensinar e aprender a complexidade de ser cidadão e as diversas sensibilidades nas quais se materializa: democrática, social, solidária, igualitária, intracultural e relativa ao meio ambiente". 
O processo formativo dos professores precisa ser constantemente repensado a partir de diversas perspectivas, por isto propõe-se uma discussão sobre profissionalidade e autonomia docente à luz de novos contextos políticos e formativos, em especial no que se refere às ações que se dão no âmbito das políticas de Pós-Graduação no Brasil após a publicação em Diário Oficial da Portaria $\mathrm{n}^{\circ}$ 080, de 16 de dezembro de 1998. Este documento dispõe sobre o reconhecimento dos Mestrados Profissionais ${ }^{2}$ e dá outras providências em relação à regulamentação desta oferta formativa institucional, instaurando novas possibilidades para a formação de diversos profissionais.

Nessa perspectiva, destaca-se que a profissionalidade docente pode ser compreendida como o que "[...] é específico na ação docente, isto é, o conjunto de comportamentos, conhecimentos, destrezas, atitudes e valores que constituem a especificidade de ser professor". (GIMENO SACRISTÁN, 1995, p. 65). Este entendimento impõe a reivindicação de novos olhares e esforços na construção de estratégias formativas inovadoras, capazes de agregar potência e compromisso no cenário de formação dos profissionais da Educação Básica. Morgado (2011) corrobora para pensar a relação entre a profissionalidade docente e a qualidade do ensino, pois considera que as competências profissionais, a cultura e a identidade profissional são três pilares essenciais da profissionalização para o desenvolvimento profissional docente e dão corpo a um saber que consubstancia o ensino.

A formação de professores, tanto inicial como continuada, tem sido um importante eixo de debates e uma responsabilidade que precisa ser assumida nos sistemas de ensino públicos ou privados, tendo em vista que grande parte das discussões sobre a educação escolar converge na figura do professor. Esta formação, elemento basilar para a melhoria da qualidade dos processos de ensino, precisa estar sustentada em um processo de desenvolvimento profissional que se materializa na ação e que "[...] é único e contínuo de permanente transformação, resultante do movimento interior protagonizado pelo professor em sua dialógica relação com o campo de conhecimento que lhe é pertinente e sua experiencialidade". (GUÉRIOS, 2002, p. 20). Engloba, portanto, a formação inicial e a continuada, que denominamos por formação institucional, durante a qual os conceitos de profissionalidade e autonomia docente, conforme Morgado (2011) e Gimeno Sacristán (1995), tomam corpo.

2 De acordo com o texto da Portaria normativa $\mathrm{n}^{\circ} 17$, publicada no Diário Oficial da União do dia 28 de dezembro de 2009, define-se que "O Mestrado Profissional (MP) é uma modalidade de Pós-Graduação stricto sensu voltada para a capacitação de profissionais, nas diversas áreas do conhecimento, mediante o estudo de técnicas, processos, ou temáticas que atendam a alguma demanda do mercado de trabalho". 
Nesse entendimento, a Pós-Graduação é etapa constitutiva do processo de profissionalização e, no campo da educação, poderá colaborar para o desenvolvimento da autonomia da ação docente por meio do aprofundamento do corpo de conhecimento que lhe é específico. Esta dinâmica de adensamento da formação docente é para Imbernón (2000, p. 46-47) o que a caracteriza, pois o desenvolvimento profissional do professor comporta o desenvolvimento pedagógico, o conhecimento de si mesmo e o desenvolvimento cognitivo ou teórico ao mesmo tempo, "[...] delimitado ou incrementado por uma situação profissional que permite ou impede o desenvolvimento de uma carreira docente".

Nesse amálgama pulsante que se constitui a partir do reconhecimento da responsabilidade das políticas institucionais de formação de professores, da função social destes profissionais e de suas condições objetivas de trabalho, surgem os Mestrados Profissionais da área de Educação no território brasileiro. Em 2009, com foco na "Gestão e Avaliação da Educação Pública", foi criado o primeiro Mestrado Profissional na área da Educação no Brasil na Universidade de Juiz de Fora (MG). De lá para cá, houve um forte movimento para expansão desta modalidade formativa na Pós-Graduação brasileira. Em decorrência disto, no ano de 2016 tem-se um quantitativo de 246 cursos de Pós-Graduação em Educação no Brasil, sendo 128 Mestrados Acadêmicos, 74 Doutorados e 44 Mestrados Profissionais em Educação reconhecidos pela Coordenação de Aperfeiçoamento de Pessoal de Nível Superior (CAPES), conforme os dados publicados na plataforma Sucupira ${ }^{3}$. A ampliação do número de Mestrados Profissionais de 26 no ano de 2013 para 44 em 2016 revela uma tendência crescente de oferta dessa modalidade formativa no cenário brasileiro de pós-graduação. Para uma melhor percepção desta realidade, os dados foram organizados e são apresentados no Quadro 1.

Os números mencionados, mesmo considerando os limites que impõem uma abordagem quantitativa, dão um panorama do avanço dos debates sobre os Mestrados Profissionais na área da Educação e convidam a ampliar esta análise sob diferentes pontos de vista e com o intuito de contribuir na formação qualificada de profissionais da Educação Básica e nas reflexões sobre profissionalismo, profissionalização e profissionalidade docente. Sob esta ótica, é imperativo sublinhar que todo este processo de ampliação do número de Mestrados Profissionais ocorre sob a determinação de uma estrutura cultural e de um clima político e social concreto que produz modificações nas políticas públicas educacionais relacionadas à formação dos profissionais da Educação Básica,

3 Plataforma Sucupira: Disponível em: <https://sucupira.capes.gov.br/sucupira/public/ consultas/coleta/programa/quantitativos/quantitativoIes.jsf?aeaAvaliacao=38\&areaConhecimen to $=70800006>$. Acesso em: 22 set. 2016. 
QUADRO 1 - DISTRIBUIÇÃO DE CURSOS DE MESTRADO PROFISSIONAL POR ESTADO

\begin{tabular}{lcc}
\hline Estado & $\mathbf{N}^{\mathbf{0}}$ de Cursos & $\mathbf{\%}$ \\
\hline Distrito Federal & 1 & 2 \\
Manaus & 1 & 2 \\
Mato Grosso & 1 & 2 \\
Rio de Janeiro & 1 & 2 \\
Roraima & 1 & 2 \\
Santa Catarina & 1 & 2 \\
Tocantins & 1 & 2 \\
Paraíba & 2 & 5 \\
Paraná & 2 & 5 \\
Pernambuco & 3 & 7 \\
Rio Grande do Sul & 5 & 12 \\
Bahia & 6 & 14 \\
Minas Gerais & 7 & 16 \\
São Paulo & 12 & 27 \\
Total & $\mathbf{4 4}$ & $\mathbf{1 0 0}$ \\
\hline
\end{tabular}

FONTE: Plataforma Sucupira. Acesso em: 22 set. 2016.

sob pena de se realizar uma reflexão descontextualizada de suas dinâmicas e implicações mais amplas.

Esses Mestrados, ao tomarem como foco, em sua grande maioria, a qualificação do trabalho dos profissionais que atuam nas escolas de Educação Básica, tendem a reforçar ou provocar o compromisso da Pós-Graduação com a formação de professores e, assim, dar respostas às expectativas sociais no que se refere à qualificação do trabalho docente. Neste âmbito, a discussão sobre a autonomia e a profissionalidade docente adquire relevo na topografia do contexto educativo-escolar e lugar de destaque quando se alinha ao próprio processo de ressignificação do papel e do status social dos profissionais que atuam nas escolas, considerando suas históricas lutas políticas.

No tocante à formação de professores para a Educação Básica, Mindal e Guérios (2013, p. 25) ressaltam que parte da complexidade do campo educativo " [...] advém da atividade dos professores por pertencerem a um grupo de profissões que lidam com formação e desenvolvimento de pessoas; com exigências feitas em termos educacionais e sociais; com atribuições específicas da profissão; e com diversidade de campos e níveis de ensino". A qualificação dessa formação é, pois, fundamental. Tão importante, também, seria considerar que as características dos Mestrados Profissionais no campo da Educação 
se constituem como um possível contributo para a melhoria da formação dos profissionais da Educação Básica, aumentando sua autonomia de ação a partir do aprimoramento de sua profissionalidade e, portanto, sendo merecedores de acompanhamento e análises mais aprofundadas.

$\mathrm{Na}$ mesma direção, seria relevante sublinhar e, ao mesmo tempo, problematizar os dados que apontam Mindal e Guérios (2013) ao afirmarem que a pouca atratividade da carreira, a falta de professores para a Educação Básica e questões curriculares pertinentes à formação inicial, entre outras temáticas relativas à formação docente, são elementos nodais e complementares para a compreensão da complexidade do campo educativo e das intempéries que solavancam o sistema público de ensino brasileiro e alteram as condições profissionais dos professores.

Bastante comuns no discurso pedagógico, a autonomia e a profissionalidade docente se constituem em conceitos fundamentais na análise de novas propostas formativas voltadas à formação de profissionais que atuam na Educação Básica. Por isso, optou-se por confrontar a lógica da concepção de um Mestrado Profissional com essas concepções que, em essência, se fundam no estímulo à reflexão e à valorização da intelectualidade dos professores, na ideia de relação entre as qualidades da prática profissional e no que se requer do trabalho docente. No mesmo caminho, Contreras (2002) complementa ao afirmar que falar em profissionalidade significa não só descrever o desempenho do trabalho de ensinar, mas também expressar valores e pretensões que se deseja alcançar e desenvolver nesta profissão.

Como em qualquer outro tema a ser abordado no âmbito das Ciências Sociais e da Educação, a autonomia e a profissionalidade docente não se constituem em temas que poderiam ser considerados ingênuos em relação à formação de qualquer grupo de profissionais. Neste caso, em especial, os professores e pedagogos que atuam na Educação Básica se caracterizam por ter uma atuação impregnada de fortes relações políticas e sociais, o que lhes atribui grande responsabilidade e necessidade de compromisso no seu labor cotidiano, tendo em vista que se constituem em importantes agentes de transformação social.

Sendo assim, neste artigo, se toma como desafio o esforço de estabelecer uma relação entre o processo de implementação de um Programa de Pós-Graduação na área da Educação na Universidade Federal do Paraná (UFPR) e o processo de desenvolvimento profissional docente, entendido como único, contínuo e constituído pela formação institucional e pela experiencial, a partir da compreensão dos conceitos de profissionalidade e autonomia docente.

No que tange à compreensão aqui adotada dos conceitos fundantes desta reflexão, buscou-se em Contreras (2002) a definição de autonomia dos profes- 
sores. O autor sustenta sua argumentação a partir da análise de três concepções diferentes sobre a profissão docente, recorrendo aos estudos de Schön, Stenhouse e Giroux, em suas respectivas abordagens sobre o professor como profissional reflexivo, o professor como pesquisador o e professor como intelectual crítico, e afirma que

[...] a autonomia profissional não se proporia a definir uma qualidade presente. Enquanto emancipação, a autonomia suporia um processo contínuo de descobertas e de transformação das diferenças entre nossa prática cotidiana e as aspirações sociais e educativas de um ensino guiado pelos valores da igualdade, justiça e democracia. Um processo contínuo de compreensão dos fatores que dificultam não só a transformação das condições sociais e institucionais do ensino, como também nossa própria consciência. (CONTRERAS, 2002, p. 85).

Nesse sentido e retomando o conceito de profissionalidade abordado por Gimeno Sacristán (1995), se assume que o processo de construção da autonomia docente requer estratégias formativas que permitam repensar o que é específico da ação docente, ou seja, o próprio processo de ensino em relação à transformação social, porque a autonomia profissional dos professores não estaria desligada do seu propósito político, nem de seu compromisso social, ou seja, das aspirações das comunidades para criar seus próprios processos de participação e decisão nos assuntos que afetam suas vidas. (CONTRERAS, 2002).

Como seu locus da ação profissional, a escola é lugar em que residem as motivações, a inquietação e os problemas que motivam a ação e a formação dos professores. Esta última, por ser um processo contínuo de descobertas e transformações que se dá ao longo da vida, articulando formação experiencial e institucional, materializa-se como o seu próprio desenvolvimento profissional (GUÉRIOS, 2002) e constitui-se desafiante para a compreensão dos aspectos teóricos e práticos relacionados ao ensino. Por isto, interessa-nos compreender um processo de formação institucional que toma como eixo o desenvolvimento profissional docente e problematiza as questões relacionadas à escola. Mais especificamente, trata-se aqui de promover uma reflexão sobre a estruturação e implementação de um Programa de Pós-Graduação na área da Educação articulado e proposto pela Universidade Federal do Paraná (UFPR) e que toma como temática central a teoria e a prática de ensino. 


\section{O processo de estruturação do Programa de Pós-Graduação em Educação: Teoria e Prática de Ensino da UFPR}

A elaboração da proposta de constituição de um Programa de Pós-Graduação em Educação a partir da oferta de um curso de mestrado em modalidade profissional foi um tema bastante discutido entre os profissionais do Setor de Educação da UFPR. Os estudos e discussões sobre os fundamentos formativos, assim como sobre a viabilidade pedagógica e institucional de implementação de um Programa de Pós-Graduação stricto sensu de natureza profissional para o campo da Educação iniciaram no ano de 2008, antes mesmo da publicação em Diário Oficial da Portaria Normativa n ${ }^{\circ}$ 17, de 28 de dezembro 2009, que dispõe sobre o Mestrado Profissional no âmbito da CAPES.

De início, houve certa resistência à ideia de um Mestrado Profissional devido às características formativas inicialmente divulgadas pelas instâncias oficiais, que, na percepção de alguns, poderia comprometer a qualidade da Pós-Graduação, historicamente conquistada. Os argumentos estiveram sustentados nas características estruturais dos Mestrados Profissionais, no perfil do corpo docente e nas propostas das políticas e do financiamento da Pós-Graduação no Brasil ou mesmo no posicionamento de algumas instituições representativas de professores e pesquisadores na área da Educação. Estes questionamentos e resistências ocorreram em diferentes Instituições de Ensino Superior, tal como constataram Fischer e Fritsch (2013), o que é compreensível devido à cultura existente em relação à Pós-Graduação na área de Educação, à época. Sobre esta resistência, Menandro (2010, p. 368) manifesta sua perplexidade pelo fato de que "[...] as reações negativas que a proposta de nova concepção de Mestrado gerou em diversas áreas, sem que todas as suas potencialidades tivessem sido discutidas, evidenciou estar em jogo um processo assemelhado à neofobia”, ou seja, um medo ao novo, mas que não foi impeditivo de ação e inovação.

Mesmo reconhecendo as dificuldades e limites do processo, um grupo de profissionais que argumentavam sobre a necessidade de ampliar a oferta da Pós-Graduação, tendo em vista a grande demanda local e regional existente, em consonância com a necessidade de responder aos compromissos sociais da universidade em relação à Educação Básica, tomou para si o desafio de elaborar uma proposta de Mestrado Profissional orientado à formação de professores. A partir de 2011, este grupo debruçou-se sobre a tarefa de elaborar uma proposta a ser submetida à avaliação da equipe da Coordenação de Aperfeiçoamento de Pessoal de Nível Superior (CAPES), órgão responsável pela regulamentação da Pós-Graduação no Brasil, com vista a atender aos requisitos mínimos exigi- 
dos e de forma coerente com o formato do aplicativo para propostas de cursos novos (APCN).

Em 2012 a instituição recebeu o retorno positivo sobre a aprovação do Programa de Pós-Graduação em Educação: Teoria e Prática de Ensino. Com este novo cenário instaurado, se constituiu o desafio de intensificar na prática o compromisso institucional com a formação de profissionais para atuar na Educação Básica. Esta iniciativa, materializada pela possibilidade de ofertar o curso de Mestrado Profissional, também representou uma resposta concreta à forte procura pela formação nos programas de Pós-Graduação da UFPR, tendo em vista que as vagas em instituições públicas de ensino representam uma oportunidade por muitos almejada.

Nesse contexto desafiador e até então desconhecido, foram instaurados os primeiros encaminhamentos necessários para dar vida ao Programa. No ano 2013 foi realizado o primeiro processo seletivo e no mesmo ano, vale destacar, que a então diretora de Formação de Professores da Educação Básica da CAPES, Carmem Moreira de Castro Neves, em notícia veiculada pelo site da própria $\mathrm{CAPES}^{4}$, no dia 17 de outubro de 2013, ressaltava que os Mestrados Profissionais eram para o contexto brasileiro uma resposta muito eficiente e eficaz para os problemas que o professor encontra no dia a dia, pois ao mesmo tempo em que ele amplia os conhecimentos e competências destes profissionais, promovendo uma formação continuada de professores em um nível crescente de complexidade, lhes abre outras oportunidades e condições para desenvolver seu labor profissional. Esta afirmativa estimulou as ações do grupo articulador da proposta de criação do Mestrado Profissional, tendo em vista seu foco e a preocupação com a formação dos profissionais da Educação Básica.

Na mesma linha, e considerando a resistência de algumas instituições aos Mestrados Profissionais que se constituíram na área da Educação, não seria menos importante considerar o cuidado de não conivência com uma abordagem tecnicista que corresponde a um modelo de racionalidade técnica, centrado na instrumentalização dos sujeitos para a resolução de problemas por meio do domínio da técnica, pois este foi um dos temores que emergiram nos discursos dos críticos em relação à proposta. Para evitar esta conivência, a ênfase precisa estar na necessidade de estabelecimento de um diálogo crítico entre as teorias e as práticas que se desenvolvem e tomam vida nas instituições de Educação Básica, bem como na demanda de melhoria nas ações educativo-escolares ${ }^{5}$ contemporâneas e no processo de construção da autonomia dos profissionais da educação. Segundo a lógica da racionalidade técnica, a atividade profissional diz

4 Disponível em: <http://www.capes.gov.br/36-noticias/6594>. Acesso em: 22 set. 2016.

5 Neste texto, quando nos referirmos aos espaços escolares, também fazemos referência aos Centros de Educação Infantil como parte da Educação Básica. 
respeito à resolução instrumental de problemas por meio de aplicação de técnicas para solucionar problemas específicos. (SCHÖN, 2000). Em outras palavras, aplica-se na prática a teoria aprendida anteriormente. No entanto, a realidade educacional é dinâmica e não previsível em suas diferentes manifestações.

Sendo assim, essa abordagem não seria coerente com a complexidade necessária para a visão e a concepção de ações formativas necessárias para os profissionais que atuam na Educação Básica, que precisam transcender o papel de executantes para o de profissionais críticos e reflexivos, capazes de desenvolver com autonomia e profissionalidade seus atos cotidianos para dar resposta a situações complexas, que em essência se convertem em atos de formação humana e social. Essa transcendência pode ser viabilizada pelo diálogo crítico que ora acenamos, por meio de um movimento articulado continuamente entre teoria aprendida em circunstância institucional de aprendizagem e prática profissional cotidiana, em que uma fundamenta a outra, reciprocamente, pelos sentidos que se lhes vão sendo atribuídos a partir das relações que estabelecem no processo de desenvolvimento profissional.

Em hipótese alguma se nega a importância do conhecimento teórico ou se defende sua superficialização nos processos formativos dos professores. Tampouco hipervalorizamos a prática dos professores por si só como instância de produção de conhecimento. Esta abordagem refere-se à contribuição da formação institucional, neste caso pontualmente nos Mestrados Profissionais em Educação, para o desenvolvimento da autonomia docente, pois, conforme Tardif (2002, p. 216), o professor "[...] é um profissional dotado de razão e cujos saberes são regidos por certas exigências da racionalidade que lhe permitem emitir juízos diante das condições contingentes de trabalho".

\section{Corpo docente e o desenvolvimento da pesquisa: implicações para a construção da autonomia e profissionalidade docente}

O perfil do corpo docente de um programa de Pós-Graduação é um elemento fulcral na sua composição, tendo em vista que estes profissionais terão a tarefa de conduzir e orientar processos de pesquisa e ofertar disciplinas que compõem a base dos fundamentos teóricos a ser aprofundados pelos estudantes. No caso do Mestrado Profissional em Educação da UFPR, a análise do perfil dos professores mostra que há em comum entre eles várias experiências relacionadas à formação de professores e pedagogos, ou seja, um contributo anterior à promoção e melhoria da profissionalidade docente. 
Essa realidade pode ser considerada positiva em relação aos objetivos do programa, pois mais do que atender as exigências de produção científica balizadas pelos critérios de avaliação estabelecidos pela CAPES, é preciso valorizar o interesse dos docentes pelo estudo e aprofundamento das questões relacionadas à docência da Educação Básica. Mais ainda, é preciso identificar e valorizar seu compromisso com a construção da autonomia dos professores a partir da qualificação daquilo que é próprio ao seu campo profissional, ou seja, as especificidades que sustentam o processo de ensino que está relacionado com a ação docente.

De acordo com a Portaria Normativa $n^{0} 7$, de 22 de junho de 2009, que tem como objetivo regulamentar a formação dos profissionais que atuam nos Mestrados Profissionais, em seu parágrafo $1^{\circ}$ da alínea IX do Artigo $7^{\circ}$, o texto tem a seguinte redação: "O corpo docente do curso deve ser altamente qualificado, conforme demonstrado pela produção intelectual constituída por publicações específicas, produção artística ou produção técnico científica, ou ainda por reconhecida experiência profissional, conforme o caso". Por um lado, é preciso manter coerência com as normativas vigentes, mas, por outro, também é importante não perder de vista a necessidade de introduzir outros critérios para seleção de profissionais a serem credenciados para atuar nas especificidades do programa, por isso considera-se adequada a opção de avaliar a proximidade e vinculação dos docentes aos estudos que tomam a escola como locus de ação e intervenção.

Em sua identidade, de forma marcada, foi possível perceber que o Programa de Pós-Graduação em Educação: Teoria e Prática de Ensino denota uma preocupação com o fortalecimento da formação dos profissionais da Educação Básica, em especial, daqueles que atuam nas redes públicas de ensino. As pesquisas desenvolvidas neste Programa de Pós-Graduação e fomentadas em suas linhas de pesquisa têm direta relação com a realidade educativo-escolar, consideradas as suas possibilidades de análise e de intervenção sobre os processos de ensino e a profissionalidade docente.

Sobre a pesquisa, base na formação dos estudantes da Pós-Graduação, se entende que esta está para além de uma simples opção por um caminho metodológico ou formalidade, tendo em vista que se trata de uma postura e um meio para a intervenção e construção de novos conhecimentos profissionais e autonomia. Sem entrar em discussão conceitual acerca dos termos "conhecimento" e "saberes", nos é apropriada para a compreensão da natureza da pesquisa como eixo de formação no Mestrado Profissional a afirmação de Tardif (2002) que

[...] os saberes profissionais se referem ao trabalho [...] são saberes trabalhados, saberes laborados, incorporados no processo de trabalho 
docente, que só tem sentido em relação às situações de trabalho e que é nessas situações que são construídos, modelados e utilizados de maneira significativa pelos trabalhadores [...] querer estudar os saberes profissionais sem associá-los a uma situação de ensino, a práticas de ensino e a um professor seria, então, um absurdo. (TARDIF, 2002, p. 256-257).

Em relação ao saber docente, Tardif (2002) destaca que é plural, que se compõe de vários saberes provenientes de diferentes fontes e os denomina por disciplinares, curriculares, profissionais e experienciais. Esses saberes precisam ser considerados pelas instituições em suas propostas formativas, pois é sobre eles que a profissionalidade e a autonomia docente se ressignificam e tomam sentido na ação dos professores.

O exposto nos permite conjecturar que a pesquisa, quando concebida como espaço formativo, tende a possibilitar ao professor constituir-se como profissional criativo (GALIAZZI; MORAES, 2002) pela via da construção de saberes profissionais que articulam teoria e prática (TARDIF, 2002) em um processo de pesquisa com implicações na ação docente, de modo que o caminho para alcançar qualidade na formação deixe de permanecer uma incógnita (MINDAL; GUÉRIOS, 2013), apesar dos esforços historicamente despendidos. De fato, como afirmam Cevallos e Passos (2012, p. 803), “[...] a prática da pesquisa no Mestrado Profissional, ao tomar como objeto de investigação as questões relacionadas ao ensino, pode influenciar diretamente a forma como o professor lida com o conteúdo e as atividades práticas em sala de aula”. O corolário desta conjectura está na possibilidade de os Mestrados Profissionais colaborarem para a qualificação stricto sensu de professores da Educação Básica, qualificação essa que ultrapasse os parâmetros da racionalidade técnica (SCHÖN, 2000) e evite o que foi problematizado por Tardif (2002) em relação aos saberes docentes, na tentativa de viabilizar uma formação específica mais orgânica que considere teoria e prática como complementares, visto que a prática do professor-mestrando é a do seu cotidiano profissional, considerando-se todas as suas especificidades constitutivas.

\section{Objetivos e estrutura curricular do Programa: o foco na formação de professores e pedagogos}

Para além da formação para e pela pesquisa na constituição de sujeitos autônomos para o exercício de sua prática profissional, também é necessário 
pensar a formação de um profissional capaz de problematizar e intervir em seu próprio contexto de trabalho. Tomando em conta este desafio, tratou-se de compreender e interpretar as características dos objetivos adotados como norteadores do Programa de Pós-Graduação em Educação: Teoria e Prática de Ensino. Os seguintes objetivos foram estabelecidos: a) promover processo de formação complementar em uma perspectiva crítica e reflexiva necessária à atuação do professor na Educação Básica; b) relacionar os conhecimentos pedagógicos e experiências sociais às estratégias de resolução de problemas do cotidiano escolar; c) articular teorias e práticas de ensino orientadas pelos objetivos da Educação Básica; d) estimular a autonomia do professor, fornecendo-lhe instrumentos para busca por conhecimento e desenvolvimento profissional de forma permanente; e) incentivar a pesquisa, a produção de materiais e práticas pedagógicas diferenciadas para o enriquecimento do processo de ensino e aprendizagem em sua área de atuação na escola.

Certamente, a definição de objetivos e de uma estrutura curricular, por si, não garante o alcance total das pretensões pretendidas por um programa de Pós-Graduação. Todavia, estes são os balizadores principais do percurso e criam um sistema de organização de princípios e tentativas de coerência em relação às convicções pedagógicas. Nesta estrutura, se buscou os possíveis pontos que sustentam a relação do processo formativo com a construção da autonomia e da profissionalidade dos mestrandos/professores. Ao longo da leitura dos objetivos, algumas expressões denotam coerência com o que apontam Contreras (2002) e Gimeno Sacristán (1995) sobre estes conceitos, são elas: "perspectiva crítica e reflexiva"; "conhecimentos pedagógicos e experiências sociais"; "autonomia do professor"; e "desenvolvimento profissional". No entanto, é possível perceber a falta de elementos que tratem de questões mais específicas da atuação dos professores por áreas de ensino, pois estas particularidades também condicionam a atuação profissional dos professores e a qualidade de sua proposta pedagógica.

Considerando tais objetivos, seria importante apontar que a estrutura curricular deste Mestrado prevê o cumprimento de 18 créditos em disciplinas, sendo 3 delas obrigatórias e 11 eletivas. Todas as disciplinas do curso se constituem de 3 créditos (45 horas/aula), conforme segue: (1) disciplinas obrigatórias: Docência e Pesquisa; Metodologia da Pesquisa em Educação; Seminário de Pesquisa em Teoria e Prática de Ensino; (2) disciplinas eletivas: Educação e Novas Tecnologias; Epistemologia das Disciplinas Escolares; Linguagem e Prática Docente; Filosofia da Diferença e Educação; Fundamentos da Prevenção na Escola; Educação, Pedagogia e Complexidade; Educação e Processos de Criação; Prática de Ensino no Contexto da Educação Integral; A Construção do Conhecimento Científico; Escola e Produção de Sentidos; e Formação Docente e a Pesquisa sobre Processos Mediadores na Escola. 
Esses componentes curriculares, estruturados a partir da intencionalidade formativa do curso e das características e potencialidades do corpo docente, trazem consigo um desafio de articulação e manutenção da indissociabilidade entre pesquisa, ensino e extensão, pilares do modelo de Ensino Superior adotado no Brasil. O percurso relativamente flexível das disciplinas que serão realizadas durante o primeiro ano no Mestrado Profissional em Educação da UFPR é uma escolha compartilhada entre os professores orientadores e os mestrandos, com base nas características e definição dos temas de pesquisa. Este percurso toma como foco o desenvolvimento do Trabalho de Conclusão de Curso, que, neste caso, se constitui em uma dissertação.

Para os professores do programa, tanto a docência como a orientação das dissertações se constitui no desafio de não apenas pesquisar sobre a formação ou atuação dos professores, bem como sobre as questões que permeiam o universo escolar, mas por pesquisar com eles sobre suas experiências cotidianas a partir de seus saberes construídos no âmbito das vivências no ensino e de seu desenvolvimento profissional. Para Contreras (2002), a autonomia dos professores, bem como a própria ideia de profissionalismo está atravessada de ponta a ponta pelas ambiguidades que a denominação de "profissional" acarreta, o que torna a tarefa de orientar o mestrando/professor ainda mais complexa, pois esta profissionalidade precisa estar considerada na própria epistemologia de construção do conhecimento. Mais do que desenvolver pesquisas sobre o ensino ou a ação docente, é preciso reivindicar um movimento ótico que permita perceber a interpretação da realidade feita com o olhar dos professores da Educação Básica, imersos e conscientes de sua realidade, autores de suas intervenções e próprios de suas decisões.

\section{Considerações finais}

O papel dos Mestrados Profissionais no contexto das políticas de Pós-Graduação no Brasil ainda está em processo de consolidação e construção de sua identidade. $\mathrm{O}$ aumento na oferta de cursos oferecidos em programas de Pós-Graduação na área de Educação que ocorreu nos últimos anos pode ser considerado um indicador de avanços e de legitimação desta modalidade formativa. No entanto, pelo pouco tempo de existência dos Mestrados Profissionais em Educação, análises futuras são necessárias para apontar resultados concretos obtidos por diferentes instituições de ensino em relação à formação dos profissionais da Educação Básica. 
Nessa tessitura, a implementação dos Mestrados Profissionais na área da Educação provoca e adensa este debate ao tentar dignificar e promover o reconhecimento da necessidade de uma formação específica para os profissionais da Educação e ao reconhecer suas especificidades e a natureza epistêmica do conhecimento, como apontam Morgado (2005) e Tardif (2002). Este debate merece ser ampliado e adensado como forma de justificar a própria existência de uma modalidade formativa diferente da modalidade acadêmica no âmbito da Pós-Graduação brasileira. O compromisso com o desenvolvimento profissional é um traço identitário fundamental que permite a construção de estruturas formativas inovadoras e com compromisso e engajamento com a formação dos profissionais da Educação Básica por meio dos Mestrados Profissionais.

Tendo em vista que a experiência analisada ainda se encontra em fase inicial de desenvolvimento, ainda não é possível antever se a formação ofertada pelo programa em pauta trará impactos em relação à melhoria na qualidade do ensino e no fortalecimento da autonomia dos professores. Se por um lado a proposta formativa dos Mestrados Profissionais pretende qualificar a formação dos profissionais da educação para potencializar sua atuação na Educação Básica, por outro, é preciso assumir que esses profissionais, muitas vezes, não encontram condições favoráveis e valorização suficiente para continuar desenvolvendo seu trabalho nas escolas ou em Centros de Educação Infantil, em especial naqueles vinculados às redes públicas de ensino. Neste sentido, vale ressaltar que não é possível desvincular a profissionalidade e a autonomia dos professores de suas condições objetivas de trabalho e do lugar em que este se constitui na sociedade.

Por fim, vale destacar que contribuir na formação dos profissionais da Educação Básica se constitui em uma clara opção política e ideológica que visa fortalecer a autonomia de um grupo de profissionais que muitas vezes é pouco reconhecido socialmente, mas que possui um papel fundamental para a concretização das mudanças sociais. E, na medida em que os Mestrados Profissionais, como no caso da experiência analisada, apontam em seus objetivos e se fundamentam na perspectiva da qualificação da ação docente a partir de um processo de formação e profissionalização, e constituem-se em instâncias formais de desenvolvimento profissional com base na reinvindicação de autonomia forjada pela relação crítica e reflexiva entre a teoria e prática, podem ser importantes contributos para as necessárias transformações sociais. 


\section{REFERÊNCIAS}

BRASIL. Ministério da Educação. Portaria Normativa nº 080, de 16 de dezembro de 1998. Dispõe sobre o reconhecimento dos mestrados profissionais e dá outras providências. Diário Oficial da República Federativa do Brasil, Brasília, 11 jan. 1999. Seção 1, p. 14.

BRASIL. Ministério da Educação. Portaria Normativa n 7, de 22 de junho de 2009. Dispõe sobre o mestrado profissional no âmbito da Fundação Coordenação de Aperfeiçoamento de Pessoal de Nível Superior. Diário Oficial da República do Brasil, 23 jun. 2009a. Seção 1, p. 31.

BRASIL. Ministério da Educação. Portaria Normativa ${ }^{0}$ 17, de 28 de dezembro de 2009. Dispõe sobre o mestrado profissional no âmbito da Fundação Coordenação de Aperfeiçoamento de Pessoal de Nível Superior - CAPES. Diário Oficial da República do Brasil, 29 dez. 2009b. Seção 1, p. 248.

CAPES. Coordenação de Aperfeiçoamento de Pessoal de Nível Superior. Mestrado Profissional: o que é? Disponível em: <http://www.capes.gov.br/avaliacao/sobre-a-avaliacao/ mestrado-profissional-o-que-e>. Acesso em: 25 set. 2016.

CEVALLOS, I.; PASSOS, L. F. O mestrado profissional e a pesquisa do professor. Revista Diálogo Educacional, Curitiba, v. 12, n. 37, p. 803-822, set./dez. 2012.

CONTRERAS, J. A autonomia de professores. 2. ed. São Paulo: Cortez, 2002.

FISCHER, B. T. D.; FRITSCH, R. Mestrado Profissional em Gestão Educacional / UNISINOS: avaliações preliminares do projeto às experiências de implementação. In: CONGRESSO INTERNACIONAL DE EDUCAÇÃO, VII.; CONGRESSO INTERNACIONAL DE AVALIAÇÃO, III., 7 a 9 out. 2013, Gramado-RS. Anais... São Leopoldo: Editora da Unisinos, 2013. CD-ROM.

GALIAZZI, M. C.; MORAES, R. Educação pela pesquisa como modo, tempo e espaço de qualificação da formação de professores de ciências. Ciênc. Educ. (Bauru), Bauru, v. 8, n. 2, 2002. Disponível em: <http://www.scielo.br/pdf/ciedu/v8n2/08.pdf $>$. Acesso em: 23 out. 2013.

GIMENO SACRISTÁN, J. The process of pedagogical reform. In: BOYED-BARRETT, O.; O'MALLEY, P. (Org.). Education reform in democratic Spain. Londres: Routledge, 1995.

GUÉRIOS, E. Espaços oficiais e intersticiais da formação docente: histórias de um grupo de professores na área de ciências e matemática. Tese (Doutorado) - UNICAMP, Campinas, 2002. Disponível em: <http://www.bibliotecadigital.unicamp.br/ document/?code $=$ vtls000259084 $>$. Acesso em: 15 out. 2016.

IMBERNÓN, F. Formação docente e profissional. Formar-se para a mudança e a incerteza. São Paulo: Cortez, 2000. 
IMBERNÓN, F. Qualidade do ensino e formação do professorado. São Paulo: Cortez, 2016.

MENANDRO, P. R. M. Documentos e Debates: Réplica 2 - Mestrado Profissional, Você Sabe Com Quem Está Falando? ANPAD. RAC, Curitiba, v. 14, n. 2, p. 367-371, mar./ abr. 2010. Disponível em: <http://www.anpad.org.br/rac>. Acesso em: 02 out. 2016.

MINDAL, C. B.; GUÉRIOS, E. Formação de professores em instituições públicas de ensino superior no Brasil: diversidade de problemas, impasses, dilemas e pontos de tensão. Educar em Revista, Curitiba, n. 50, p. 21-33, 2013.

MORGADO, J. C. Currículo e profissionalidade docente. Porto: Porto Editora, 2005.

MORGADO, J. C. Identidade e profissionalidade docente: sentidos e (im)possibilidades. Ensaio: Aval. Pol. Públ. Educ., Rio de Janeiro, v. 19, n. 73, p. 793-812, out./dez. 2011. Disponível em: $<$ http://www.scielo.br/pdf/ensaio/v19n73/04.pdf $>$. Acesso em: 11 out. 2016.

SCHÖN, D. Educando o profissional reflexivo: um novo design para o ensino e a aprendizagem. Porto Alegre: Artmed, 2000.

TARDIF, M. Saberes docentes e formação profissional. Petrópolis: Vozes, 2002.

Texto recebido em 03 de outubro de 2016. Texto aprovado em 04 de novembro de 2016. 
